\title{
Daily tonometric curves after cataract surgery
}

\author{
S Saccà, A Marletta, A Pascotto, S Barabino, M Rolando, R Giannetti, G Calabria
}

\begin{abstract}
Aim-To evaluate daily tonometric curves after cataract surgery in patients with cataract only and in patients with cataract and glaucoma.

Methods-108 patients scheduled for cataract surgery were randomly allocated to two groups: 57 patients with cataract only (normal) and 51 with cataract and primary open angle glaucoma (POAG). All patients underwent extracapsular cataract extraction (ECCE) (manual technique with long wound), phacoemulsification (automated technique with short wound), or nucleus capture (manual technique with short wound). Intraocular pressure (IOP) was measured by Goldmann tonometry in all patients every 2 hours for 12 hours before the operation and at 1 and 6 months postoperatively.

Results-79 patients completed the 6 month examination. ECCE resulted in greater reductions in IOP than the other procedures (ECCE: $27 \%$ and $36 \%$ in normal patients and those with POAG, respectively; nucleus capture: $20 \%$ and $31 \%$, respectively; phacoemulsification: $19 \%$ and $22 \%$, respectively). The fluctuations in IOP before and after surgery were not statistically significant.

Conclusion-Cataract surgery in normal patients reduces IOP but does not eliminate fluctuations which are directly proportional to the IOP value and result partly from circadian rhythms. This important finding might influence our approach to treatment of patients with glaucoma.

(Br f Ophthalmol 2001;85:24-29)
\end{abstract}

Department of Neurological and Visual Sciences, Ophthalmology R, University of Genoa, 16132 Genoa, Italy

$S$ Saccà

A Marletta

A Pascotto

S Barabino

M Rolando

G Calabria

Spedali Riuniti di Livorno, Ospedale Civile, Livorno, Italy R Giannetti

Correspondence to: Dr S Saccà

sacca@smartino.ge.it

Accepted 28 June 2000
Independent of the technique used, ${ }^{1-3}$ cataract extraction surgery induces variations in intraocular pressure (IOP) in normal patients ${ }^{4}$ and in those with primary open angle glaucoma (POAG). ${ }^{5}$ Some investigators have measured increased IOP after cataract surgery or have not reported significant tonometric variations. ${ }^{67}$ Gimbel et al found a reduction in IOP following phacoemulsification but there was a significant difference in the decrease in IOP between glaucomatous eyes treated by phacoemulsification with trabeculectomy and those treated by phacoemulsification alone. However, more recently other authors have recorded a significant reduction in IOP after cataract surgery ${ }^{9}$ without significant tonometric differences between patients with glaucoma who underwent cataract surgery alone and those who underwent combined cataract and glaucoma surgery. ${ }^{8}$ Thus, in patients with both cataract and glaucoma, surgeons must decide whether to treat only one condition or both.

The disparity in the results could result from the fact that the IOP is not stable but fluctuates daily in normal individuals and in those with POAG. ${ }^{10}$ These daily variations are also seen in patients receiving antiglaucomatous treatment. ${ }^{11}$

We have attempted to confirm the daily variations in IOP following three cataract procedures-extracapsular cataract extraction (ECCE), phacoemulsification, or nucleus capture-in normal patients and in those with POAG.

\section{Patients and methods}

Approval for this study was given by the ethics board of the ophthalmologic division of neurological sciences and vision department of Genoa University and all study patients gave written informed consent.

Between March 1997 and December 1998 108 consecutive patients (61 women, 47 men) with cataract aged 45-82 years were enrolled. Patients were divided into two groups: 57 normal patients with cataract only and 51 patients with POAG and cataract. One eye of each patient was included in the study. In patients with bilateral glaucoma treatment with $\beta$ blocking drugs was suspended during the follow up period and either dorzolamide or latanoprost, or both, were administered to eliminate possible pharmacological effects on the study eye. Patients in the two groups were randomly assigned to surgery with ECCE, phacoemulsification, or nucleus capture.

The inclusion criteria for the normal patients were: visual acuity $\leqslant 25 / 50$ (Snellen fraction); an open anterior chamber angle; no history of previous filtration surgery; pupil size $\geqslant 5 \mathrm{~mm}$ after dilatation; absence of pseudoexfoliation syndrome, diabetes, uveitis, systemic collagenopathy, and objective neurological signs; no history of use of systemic antihypertensive drugs; and no administration of corticosteroids or systemic or topical antiglaucomatous drugs during at least 38 (8) days before enrolment in the study. For the patients with POAG the inclusion criteria were: IOP values of $21-26 \mathrm{~mm} \mathrm{Hg}$ without pharmacological therapy at two or more measurements and the presence of typical perimetric glaucomatous defects found by reliable computerised visual field testing - that is, at least (a) two contiguous points with $\geqslant 10 \mathrm{~dB}$ loss in the superior or inferior Bjerrum areas compared with perimeter defined age matched controls; (b) three contiguous points with $\geqslant 5 \mathrm{~dB}$ loss in the superior or inferior Bjerrum areas; or (c) a $10 \mathrm{~dB}$ difference across the nasal horizontal midline in two or more adjacent locations. 
Table 1 Data from 79 patients who completed the 6 month follow up *

\begin{tabular}{lllllll}
\hline & $\begin{array}{l}\text { Normal } \\
\text { cases }\end{array}$ & $\begin{array}{c}\text { Age range } \\
\text { (years) }\end{array}$ & Sex & POAG cases & $\begin{array}{c}\text { Age range } \\
\text { (years) }\end{array}$ & Sex \\
\hline ECCE & 12 & $45-77$ & $4 \mathrm{M} / 8 \mathrm{~F}$ & 13 & $58-77$ & $7 \mathrm{M} / 6 \mathrm{~F}$ \\
Phaco & 13 & $56-78$ & $6 \mathrm{M} / 7 \mathrm{~F}$ & 15 & $54-82$ & $9 \mathrm{M} / 6 \mathrm{~F}$ \\
NC & 13 & $51-76$ & $7 \mathrm{M} / 6 \mathrm{~F}$ & 13 & $49-80$ & $6 \mathrm{M} / 7 \mathrm{~F}$ \\
Total & 38 & $45-78$ & $17 \mathrm{M} / 20 \mathrm{~F}$ & 41 & $49-82$ & $22 \mathrm{M} / 19 \mathrm{~F}$ \\
\hline
\end{tabular}

*The groups are homogeneous for age ( $p=$ not significant, $\chi^{2}$ test).

$\mathrm{ECCE}=$ extracapsular cataract extraction; phaco $=$ phacoemulsification, $\mathrm{NC}=$ nucleus capture; POAG = primary open angle glaucoma.

All patients underwent a complete ophthalmological examination preoperatively including slit lamp examination with and without pupil dilatation, gonioscopy, and ophthalmoscopy. IOP was measured by Goldmann tonometry every 2 hours between 08.00 hours and 20.00 hours and the results were plotted into a diurnal tonometric curve. All measurements were performed by two doctors, but the same doctor always performed the IOP measurements in the same patients. Diurnal tonometric curves were repeated 1 week (SD 4 days) before surgery $\left(\mathrm{T}_{0}\right)$ and at 1 month (SD 7 days) $\left(\mathrm{T}_{1}\right)$ and 6 months (SD 12 days) $\left(\mathrm{T}_{2}\right)$ after surgery.

Patients who presented with an IOP of more than $23 \mathrm{~mm} \mathrm{Hg}$ during the plotting of the second tonometric curve $\left(T_{1}\right)$ received topical dorzolamide three times daily; this treatment was suspended 30 days before plotting the diurnal tonometric curve 6 months after surgery $\left(\mathrm{T}_{2}\right)$.

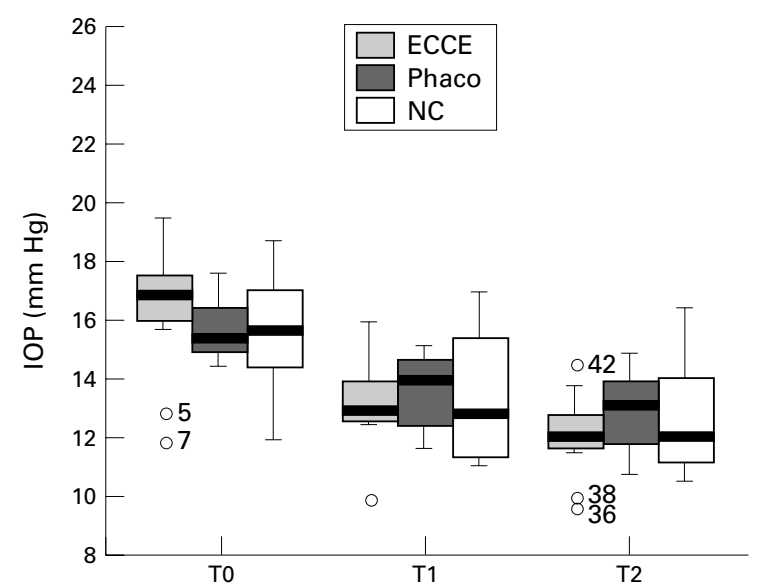

$\begin{array}{llllllll}\text { ECCE } & \text { H } 8 & \text { H } 10 & \text { H } 12 & \text { H } 14 & \text { H } 16 & \text { H } 18 & \text { H } 20\end{array}$ \begin{tabular}{|c|c|c|c|c|c|c|c|}
\hline $\mathrm{T}_{0}$ & $17.08(2.61)$ & $16.58(3.06)$ & $16.33(2.77)$ & $15.92(2.54)$ & $15.67(2.10)$ & $16.58(2.43)$ & $16.75(2.26)$ \\
\hline
\end{tabular} \begin{tabular}{|c|c|c|c|c|c|c|c|}
\hline $\mathrm{T}_{1}$ & $13.67(2.10)$ & $12.83(2.17)$ & $12.5(1.88)$ & $12.42(2.06)$ & $12.67(2.19)$ & $13.25(2.66)$ & $13.33(1.61)$ \\
\hline
\end{tabular} \begin{tabular}{|l|l|l|l|l|l|l|l|l|}
$\mathrm{T}_{2}$ & $12.92(1.68)$ & $11.83(1.47)$ & $11.58(1.31)$ & $11.17(1.75)$ & $11.5(1.83)$ & $12.08(1.78)$ & $12.92(1.51)$ \\
\hline
\end{tabular} Phaco

\begin{tabular}{|c|c|c|c|c|c|c|c|}
\hline $\mathrm{T}_{0}$ & \begin{tabular}{|l|l|}
$16.92(2.53)$ \\
\end{tabular} & $16.00(1.22)$ & $15.54(1.39)$ & $15.08(1.81)$ & \begin{tabular}{|l|l|}
$15.38(2.22)$ \\
\end{tabular} & $16.00(1.74)$ & $16.46(1.66)$ \\
\hline $\mathrm{T}_{1}$ & \begin{tabular}{|l|}
$15.15(2.03)$ \\
\end{tabular} & $13.85(1.34)$ & $13.23(1.24)$ & $13.23(2.20)$ & $13.23(1.54)$ & $13.15(1.72)$ & 13.69 (1.03) \\
\hline$T_{2}$ & 5) & 13.15 & 12.6 & 12.23 & $12.08(1.38)$ & 12.31 & $13.00(1.53)$ \\
\hline \multicolumn{8}{|l|}{ NC } \\
\hline $\mathrm{T}_{0}$ & $.46(2.57)$ & \begin{tabular}{|l|l|}
$15.92(2.18)$ \\
\end{tabular} & $15.62(3.12)$ & $15.62(2.10)$ & \begin{tabular}{|l|l|}
$15.46(2.07)$ \\
\end{tabular} & \begin{tabular}{|l}
$15.23(2.42)$ \\
\end{tabular} & $15.62(2.66)$ \\
\hline$T_{1}$ & $4.31(2.66)$ & $13.85(2.48)$ & $13.38(2.29)$ & $13.17(2.04)$ & $12.85(2.08)$ & $13.00(2.31)$ & $13.54(2.40)$ \\
\hline T & $14.00(2.42)$ & $13.23(2.35)$ & $12.31(2.02)$ & $12.38(1.71)$ & $12.77(1.88)$ & $11.92(2.29$ & $12.85(2.0$ \\
\hline
\end{tabular}

Figure 1 Mean (SD) intraocular pressure (IOP) of the tonometric surveys at 2 hour intervals between 08.00 hours and 20.00 hours in the normal group. The graph shows the average daily values that resulted from the different surgical techniques. The box plot shows the singular variables between the 25 th and 75 th percentiles; the horizontal lines represent the median values and the vertical lines represent the 5th and 95th percentiles. The outliers are identified by the patient case number. ECCE = extracapsular cataract extraction; phaco $=$ phacoemulsification; $N C=$ nucleus capture; $H=$ hour; $T_{0}=$ before surgery; $T_{1}=1$ month after surgery; $T_{2}=6$ months after surgery.
On the day of surgery all patients received short acting mydriatic agents: $0.5 \%$ tropicamide, phenylephrine $10 \%$, and cyclopentolate $1 \%$ were used for pupillary dilatation and diclofenac to maintain mydriasis. Peribulbar anaesthesia was induced with lignocaine hydrochloride $2 \%$, bupivacaine hydrochloride $0.75 \%$ with 1:200 000 adrenaline, and 150 IU hyaluronidase. All operations were performed by the authors (nucleus capture by SCS, phacoemulsification by MR, and ECCE by GC). All patients with POAG received a $100 \mathrm{ml}$ intravenous drip of mannitol 1 hour before surgery.

During the operation a metallic blepharostat was used and the superior rectus muscle was not fixed with a suture.

\section{SURGICAL PROCEDURES}

ECCE

A $15 \mathrm{~mm}$ fornix based conjunctival flap was created and wet field cautery was performed for haemostasis. A $12 \mathrm{~mm}$ scleral incision was made with a steel blade $2 \mathrm{~mm}$ posterior to the surgical limbus. The anterior chamber (AC) was entered at 10 o'clock with a 21 gauge needle. An anterior capsulotomy was done with the same needle under water infusion. The nucleus was rocked free in the posterior chamber and the incision was enlarged to $11 \mathrm{~mm}$. The nucleus was removed using pressure at the 6 and 12 o'clock limbus positions. The incision was closed with 8-0 silk sutures. Manual irrigation/aspiration of cortical material was performed with a McIntyre cannula. A $6.5 \mathrm{~mm}$ polymethylmethacrylate (PMMA) intraocular lens (IOL) was inserted into the posterior chamber and fixed in the sulcus under an air bubble. Wounds were closed with a continuous 10-0 nylon monofilament suture.

\section{Phacoemulsification}

A $3.2 \mathrm{~mm}$ corneal tunnel was created using a steel keratome in an oblique diving entry position. The AC was maintained with sodium chondroitin $4.0 \%$ and sodium hyaluronate $3.0 \%$ (Viscoat, Alcon). A $5.0 \mathrm{~mm}$ circular continuous capsulorhexis was performed. After hydrodissection a phacoemulsification tip was used to remove the lens nucleus; residual cortical material was removed by irrigation and aspiration. When cortical aspiration was complete, the incision was enlarged using a $5.2 \mathrm{~mm}$ steel keratome. A $5.0 \mathrm{~mm}$ PMMA posterior chamber IOL was placed in the capsular bag. The viscoelastic was aspirated and the incision was closed with a single radial stitch.

\section{Nucleus capture}

A rectilinear $5.2 \mathrm{~mm}$, half thickness corneal incision was made with a disposable knife on the astigmatism axis. A $3.2 \mathrm{~mm}$ corneal tunnel was created with a precalibrated knife. The AC depth was maintained with sodium hyaluronate, a $6.0 \mathrm{~mm}$ capsulorhexis was created, and hydrodissection and hydrodelineation were performed. The nucleus was moved into the AC by injecting a viscoelastic between the nucleus and the epinucleus. Nucleus capture was performed after the tunnel was enlarged to $5.2 \mathrm{~mm}$ using a bimanual manoeuvre in which 


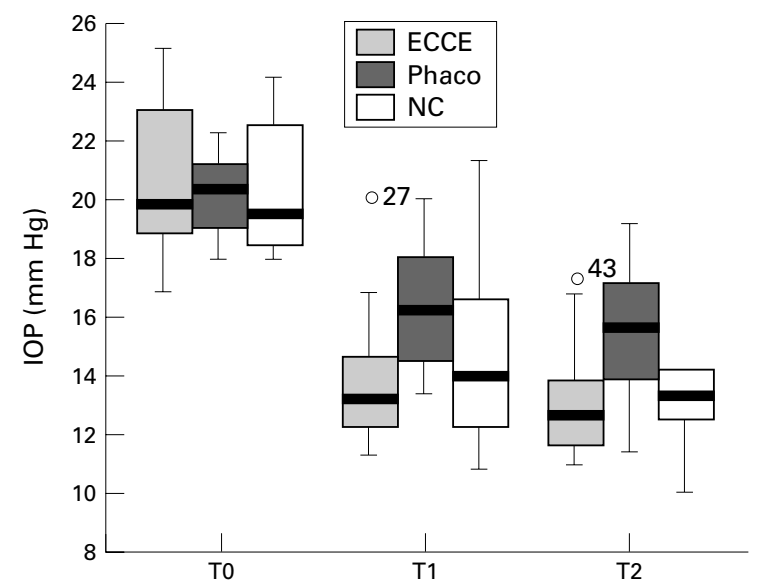

$\begin{array}{llllllll}\text { ECCE } & \text { H } 8 & \text { H } 10 & \text { H } 12 & \text { H } 14 & \text { H } 16 & \text { H } 18 & \text { H } 20\end{array}$

\begin{tabular}{|c|c|c|c|c|c|c|c|}
\hline $\mathrm{T}_{0}$ & $22.38(2.79)$ & $20.38(2.87)$ & $20.46(3.71)$ & $19.69(4.25)$ & $19.15(3.94)$ & $20.23(4.99)$ & $21.85(3.72)$ \\
\hline $\mathrm{T}_{1}$ & $15.38(3.81)$ & $14.08(3.07)$ & $13.54(2.32)$ & $13.31(2.32)$ & $13.54(2.37)$ & $13.69(3.05)$ & $14.08(3.08)$ \\
\hline $\mathrm{T}_{2}$ & $14.15(2.53)$ & $13.38(2.27)$ & $13.00(2.13)$ & $12.92(2.11)$ & $12.69(2.26)$ & $12.92(2.02)$ & $13.15(2.64)$ \\
\hline
\end{tabular}

Phaco

\begin{tabular}{|c|c|c|c|c|c|c|c|}
\hline $\mathrm{T}_{0}$ & $23.40(2.32)$ & $21.47(3.20)$ & $20.40(3.78)$ & $17.73(1.91)$ & $18.80(1.66)$ & $18.60(2.38)$ & $19.80(3.30)$ \\
\hline $\mathrm{T}_{1}$ & $18.67(2.99)$ & $16.87(2.75)$ & $16.33(2.66)$ & $15.47(2.29)$ & $15.60(1.76)$ & $16.13(2.59)$ & $16.20(2.34)$ \\
\hline $\mathrm{T}_{2}$ & $17.13(3.07)$ & $16.07(2.66)$ & $15.40(2.47)$ & $15.13(2.53)$ & $14.80(2.14)$ & $15.40(2.72)$ & $15.53(2.26)$ \\
\hline
\end{tabular}

$\mathrm{NC}$

\begin{tabular}{|c|c|c|c|c|c|c|c|}
\hline $\mathrm{T}_{0}$ & $23.15(2.48)$ & $20.38(2.90)$ & $19.69(3.09)$ & $18.46(4.01)$ & $18.62(3.01)$ & $19.62(3.45)$ & $22.69(2.32)$ \\
\hline $\mathrm{T}_{1}$ & $16.62(3.99)$ & $14.62(3.62)$ & $14.54(3.15)$ & $14.23(3.06)$ & $14.31(3.35)$ & $14.23(3.11)$ & $15.23(4.34)$ \\
\hline $\mathrm{T}_{2}$ & $16.31(4.09)$ & $14.08(3.12)$ & $13.46(3.73)$ & $13.00(3.44)$ & $13.23(3.06)$ & $13.92(2.93)$ & $14.69(3.50)$ \\
\hline
\end{tabular}

Figure 2 Mean (SD) intraocular pressure (IOP) of the tonometric surveys at 2 hour intervals between 08.00 hours and 20.00 hours in the patients with primary open angle glaucoma. The graph shows the average daily values produced by the different surgical techniques. IOP was highest at 08.00 hours, decreased during the day and then increased in the evening. $E C C E=$ extracapsular cataract extraction; phaco = phacoemulsification; $N C$ $=$ nucleus capture; $H=$ hour; $T_{0}=$ before surgery; $T_{1}=1$ month after surgery; $T_{2}=6$ months after surgery.

a spoon was introduced under the nucleus and a bent spatula was used over the nucleus. The nucleus was then extracted through the tunnel. After the AC was rinsed to remove epinuclear fragments the cortex was aspirated using a McIntyre cannula. A $5.0 \mathrm{~mm}$ IOL was implanted in the capsular bag. The viscoelastic

Table 2 Mean decreases in intraocular pressure 1 month $\left(T_{1}\right)$ and 6 months $\left(T_{2}\right)$ after each of the surgical procedures

\begin{tabular}{llllll}
\hline & \multicolumn{2}{l}{ Normal } & & \multicolumn{2}{l}{ POAG } \\
\cline { 2 - 3 } \cline { 5 - 6 } \cline { 5 - 6 } & $T_{1}$ & $\mathrm{~T}_{2}$ & & $\mathrm{~T}_{1}$ & $\mathrm{~T}_{2}$ \\
\hline ECCE & $-21.10 \%$ & $-26.90 \%$ & & $-32.28 \%$ & $-36.02 \%$ \\
Phaco & $-14.23 \%$ & $-19.06 \%$ & & $-17.78 \%$ & $-21.92 \%$ \\
NC & $-14.40 \%$ & $-19.52 \%$ & & $-27.24 \%$ & $-30.80 \%$ \\
\hline
\end{tabular}

All three surgical procedures resulted in statistically significant $(p<0.001$, one way analysis of variance with Scheffe's test) differences in intraocular pressures compared with the preoperative values.

ECCE $=$ extracapsular cataract extraction; phaco $=$ phacoemulsification, $\mathrm{NC}=$ nucleus capture; POAG $=$ primary open angle glaucoma .

Table 3 Differences in intraocular pressure (IOP) ( $\mathrm{mm} \mathrm{Hg}$ ) between baseline and 1 month after surgery $\left(T_{1}-T_{2}\right)$, between 1 month and 6 months after surgery $\left(T_{2}-T_{1}\right)$, and between baseline and 6 months after surgery $\left(T_{2}-T_{0}\right)$

\begin{tabular}{|c|c|c|c|c|c|c|}
\hline & \multicolumn{3}{|c|}{ Normal } & \multicolumn{3}{|l|}{$P O A G$} \\
\hline & $T_{1}-T_{0}$ & $\mathrm{~T}_{2}-\mathrm{T}_{1}$ & $\mathrm{~T}_{2}-\mathrm{T}_{0}$ & $\mathrm{~T}_{1}-\mathrm{T}_{0}$ & $\mathrm{~T}_{2}-\mathrm{T}_{1}$ & $\mathrm{~T}_{2}-\mathrm{T}_{0}$ \\
\hline ECCE & -3.46 & -0.95 & -4.42 & -6.65 & -0.77 & -7.42 \\
\hline Phaco & -2.26 & -0.77 & -3.03 & -3.56 & -0.83 & -4.39 \\
\hline $\mathrm{NC}$ & -2.26 & -0.80 & -3.07 & -5.55 & -0.73 & -6.27 \\
\hline
\end{tabular}

In both groups of patients the difference between the IOP values 1 month after surgery and 6 months after surgery was about $1 \mathrm{~mm} \mathrm{Hg}$ (not statistically significant).

$\mathrm{ECCE}=$ extracapsular cataract extraction; phaco = phacoemulsification; $\mathrm{NC}=$ nucleus capture; POAG $=$ primary open angle glaucoma . was aspirated from the $\mathrm{AC}$ and the tunnel was closed with one 10-0 nylon suture.

All patients received topical tobramycin and dexamethasone eye drops were prescribed five times daily for 2 weeks and three times daily for an additional 7 days.

STATISTICAL ANALYSIS

Statistical analysis was performed by AM. Using sPss 6.0 software, the data were analysed by parametric descriptive and probabilistic statistics to define all study variables. To evaluate the homogeneity of the patient groups, the $\chi^{2}$ test was performed at the threshold $(p=0.05)$ after patients were divided into groups based on 5 year age intervals.

One way analysis of variation (ANOVA) with Scheffe's test was used to evaluate internal variations and to compare data from the normal and POAG groups before surgery $\left(T_{0}\right)$ and at 1 month $\left(T_{1}\right)$ and 6 months $\left(T_{2}\right)$ postoperatively. ANOVA was also used to compare the effects of the three surgical procedures on IOP.

The percentage daily variation ( $Z$ score) was determined using the formula $\mathrm{Z}$ score = $(x-<x>) /\langle x\rangle$ where $\langle x\rangle$ is the daily mean.

\section{Results}

Seventy nine patients (40 women) aged 45-82 years underwent a follow up examination 6 months postoperatively (Table 1 ). Twenty nine patients did not complete the study: one died, two developed surgical complications, six took drugs not included in the protocol, and $20 \mathrm{did}$ not undergo follow up examinations.

Our results showed that all cataract procedures resulted in decreased IOP levels in normal patients (Fig 1) and in patients with POAG (Fig 2). ECCE resulted in the greatest decrease in IOP. The tonometric differences at 1 and 6 months postoperatively were statistically significant $(\mathrm{p}<0.001)$ with all surgical techniques (Table 2).

The average decreases obtained 1 month after surgery with ECCE were $3.46 \mathrm{~mm} \mathrm{Hg}$ in normal patients and $6.65 \mathrm{~mm} \mathrm{Hg}$ in patients with POAG. In the subsequent months there was an additional decrease of almost $1 \mathrm{~mm} \mathrm{Hg}$ which was not statistically significant. With phacoemulsification and nucleus capture the greatest decrease in IOP was seen after 6 months, but the decrease was not significant after the first month (Table 3).

When only the reduction in IOP was considered, ECCE was the most efficacious surgical technique and resulted in an average fall in IOP of $27 \%$ in normal patients and $36 \%$ in patients with POAG. Nucleus capture resulted in falls of $19 \%$ and $30 \%$, respectively, and phacoemulsification in falls of $19 \%$ and $22 \%$, respectively (Table 2). No significant difference was seen between phacoemulsification and nucleus capture but ECCE produced statistically significant differences at $T_{1}$ and $T_{2}$ compared with the other procedures $(p=0.0427$ and $p=0.0260$, respectively, one way ANOVA with Scheffe's test).

At the end of the follow up period three patients who underwent phacoemulsification 
Table 4 Intraocular pressure fluctuations in normal patients and patients with primary open angle glaucoma (POAG) treated with the three surgical procedures

\begin{tabular}{|c|c|c|c|c|c|c|}
\hline & \multicolumn{3}{|l|}{ Normal } & \multicolumn{3}{|l|}{$P O A G$} \\
\hline & $T_{0}$ & $\mathrm{~T}_{1}$ & $\mathrm{~T}_{2}$ & $\mathrm{~T}_{0}$ & $\mathrm{~T}_{1}$ & $\mathrm{~T}_{2}$ \\
\hline ECCE & $-0.75,+0.67$ & $-0.54,+0.71$ & $-0.50,+0.92$ & $-1.44,+1.79$ & $-0.64,+1.44$ & $-0.48,+0.98$ \\
\hline Phaco & $-0.84,+1.01$ & $-0.49,+1.51$ & $-0.80,+1.81$ & $-2.30,+3.37$ & $-1.00,+2.20$ & $-0.84,+1.50$ \\
\hline NC & $-0.47,+0.76$ & $-0.60,+0.87$ & $-0.87,+1.36$ & $-1.91,+2.78$ & $-0.59,+1.79$ & $-1.10,+2.21$ \\
\hline
\end{tabular}

The differences were not statistically different.

ECCE $=$ extracapsular cataract extraction; phaco $=$ phacoemulsification; $\mathrm{NC}=$ nucleus capture; $\mathrm{T}_{0}=$ before surgery; $\mathrm{T}_{1}=1 \mathrm{month}$ after surgery; $T_{2}=6$ months after surgery.

and two who underwent nucleus capture had at least one IOP measurement higher than $21 \mathrm{~mm} \mathrm{Hg}$ during the plotting of the daily tonometric curve.

This study has provided a global picture of variations in IOP after cataract surgery and indicates that IOP levels fluctuate daily before and after surgery in all study patients (Table 4 ). The fluctuations were not statistically significant in either group before or after surgery, independent of the technique used. The daily fluctuations in IOP occurred generally in the same manner in the two patient groups: higher IOP values were found at 08.00 hours and lower values were found in the afternoon (Figs 1 and 2). In patients with POAG these fluctuations were reduced when the IOP levels were lower (Table 4).

\section{Discussion}

At the end of the follow up period $12.2 \%$ of the patients with POAG had IOP values above $21 \mathrm{~mm} \mathrm{Hg}$ at least once during the plotting of the diurnal tonometric curve. In the remaining patients with POAG a reduction in IOP was observed 1 month postoperatively as in the normal patients.

It is noteworthy that IOP levels fluctuate, ${ }^{10}$ which makes plotting of accurate diurnal tonometric curves important. On the other hand, pressure peaks are reported to be important in determining the extent of glaucomatous damage. $^{12}$

In our study population one patient in the POAG group had an IOP of $24 \mathrm{~mm} \mathrm{Hg}$ at 16.00 hours at the 1 month examination and $23 \mathrm{~mm} \mathrm{Hg}$ at 16.00 hours at the 6 month examination. During the remainder of the day the tonometric measurements were all equal to or lower than $20 \mathrm{~mm} \mathrm{Hg}$ (Fig 3). This case indicates that it can be difficult to obtain precise measurements in a patient with glaucoma. Furthermore, when the IOP decreased we also saw stabilisation of the curve in

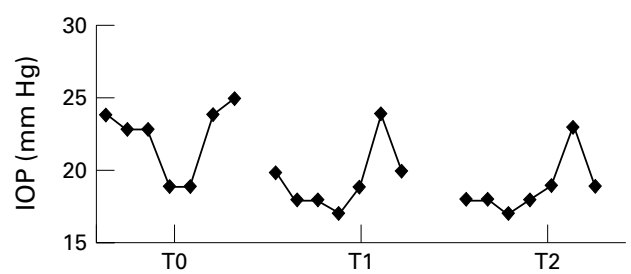

Figure 3 Intraocular pressure (IOP) in the left eye of an 82 year old woman with primary open angle glaucoma of almost 10 years' duration preoperatively $\left(T_{0}\right), 34$ days after phacoemulsification $\left(T_{1}\right)$, and at the end of follow up $\left(T_{2}\right)$. Tonometric decompensation is evident only at 16.00 hours. patients with POAG, which confirms that daily IOP fluctuations are directly proportional to the IOP level. ${ }^{10}$

These fluctuations can be partly attributed to circadian rhythms, and our study confirmed that there were no statistically significant differences in IOP fluctuations before and after surgery in normal patients and in those with POAG. Furthermore, the curves observed in the two patient groups had a similar concave profile with higher values in the morning, decreasing in the afternoon and increasing again in the evening (Fig 4).

Based on these results, cataract extraction decreases the IOP level but does not eliminate the circadian rhythm. The exact mechanism by which cataract surgery improves IOP is unclear; many hypotheses have been presented in the literature (Fig 5), all based on three pathogenic mechanisms: hyposecretion, increase in prostaglandins, and increase in aqueous flow.

Cataract removal is associated with biochemical or blood-aqueous barrier changes; such changes have been shown to influence IOP levels. ${ }^{19}$ Phacoemulsification produces free radicals $^{29}$ that may act as inflammatory
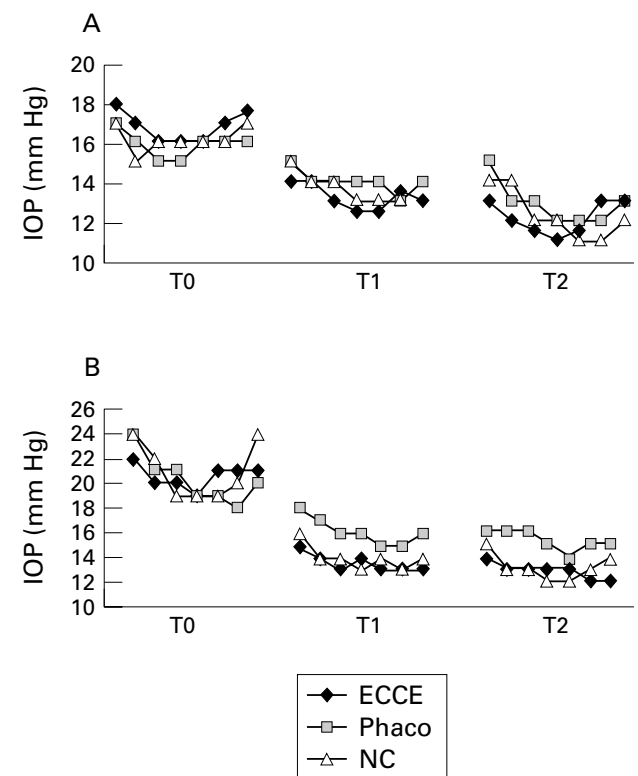

Figure 4 Mean intraocular pressure (IOP) in $(A)$ normal patients and $(B)$ patients with primary open angle glaucoma before surgery $\left(T_{\nu}\right)$ and at 1 month $\left(T_{\nu}\right)$ and 6 months $\left(T_{2}\right)$ postoperatively. The IOP values have a concave profile which confirms circadian rhythms. IOP fluctuations at the end of the follow up period are always present, even though the ranges decrease as in the group with primary open angle glaucoma. ECCE = extracapsular cataract extraction; phaco $=$ phacoemulsification $; C=$ nucleus capture. 
Ciliary

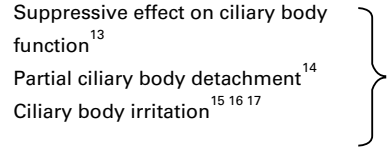

Hyposecretion of aqueous humour 2027

Biochemical

Aqueous humour changes 21819 Increasing permeability of the blood-aqueous barrier ${ }^{2192021}$

IOL release

$$
\begin{aligned}
& \text { IOL position } \\
& \text { Traction on ciliary body }^{20} \\
& \text { Chronic inflammation }^{15}
\end{aligned}
$$

IOL thickness 223 Trabecular space widening ${ }^{172}$ Schlemm breakdown prevention ${ }^{15}$

$\begin{array}{ll}\text { Morphological } & \begin{array}{l}\text { Increase in anterior chamber } \\ \text { Space enlargement }\end{array} \\ & \\ \begin{array}{l}\text { Surgery procedure } \\ \text { related }\end{array} & \begin{array}{l}\text { Small corneal incision } \\ \text { Washing out effect on trabecular }^{18} \\ \text { meshwork }^{927} \\ \text { Capsulorhexis size }^{23} \\ \text { Clear cornea incision }^{14}\end{array} \\ & \begin{array}{l}\text { Improved } \\ \text { outflow }^{26181922} \\ \text { facility }^{2619}\end{array}\end{array}$

Figure 5 Factors that induce reduction in intraocular pressure (IOP) after cataract surgery. The various hypotheses focus on three principal factors that can cause an increase in aqueous flow with increased release of endogenous prostaglandins. IOL $=$ intraocular lens. analogues stimulate the formation of $\mathrm{PGE}_{2}$, $\mathrm{PGD}_{2}$, and $\mathrm{PGF}_{2 \alpha}$ in the iris and ciliary muscle which interact with the prostaglandin receptor to stimulate phospholipase $\mathrm{A}_{2}$ and release amino acids for prostaglandin synthesis. $^{40}$ Relaxation of ciliary muscles by $\mathrm{PGF}_{2 \alpha}$ and its analogues via release of endogenous $\mathrm{PGE}_{2}$, a potent activator of the adenylate cyclase system, could partly explain how these prostaglandins may increase uveoscleral outflow and consequently lower IOP. ${ }^{40}$

Meyer et al have shown that in phacoemulsification the flow coefficient of aqueous humour remains raised compared with the preoperative values. ${ }^{18}$ We believe that postoperative inflammation and subsequent prostaglandin release have a central role in decreasing IOP which could be the result of increased uveoscleral flow after an increase in endogenous postoperative prostaglandin synthesis (Fig 3), which confirms the results of Kerstetter et al. ${ }^{41}$

In our opinion, surgical techniques that require short wounds induce less inflammation and less prostaglandin release than techniques requiring longer wounds. However, manual techniques stimulate greater endogenous synthesis of prostaglandins, causing a more significant reduction in IOP.

In conclusion, cataract surgery induces tonometric compensation in more than $80 \%$ of patients with POAG with an IOP under $26 \mathrm{~mm} \mathrm{Hg}$ and results in a reduction in the pharmacological doses used preoperatively. Even though follow up in the present study was limited to 6 months, IOP reductions have been seen up to 7 years after cataract surgery. ${ }^{17}$ The choice of the surgical technique is dependent on the surgeon, but the decrease in IOP is probably related to subclinical inflammation. Our work suggests that combined procedures should be used in eyes that are at risk of further damage to the optic nerve or in those with significant optic nerve damage and visual field loss. Those patients who do not have profound optic nerve damage and visual field loss might benefit from clear corneal cataract surgery alone. Further studies are needed to expand our knowledge concerning the safe approach to cataract surgery in patients with glaucoma. Finally, we emphasise the importance of diurnal tonometric curves which may contribute to greater control of IOP in these patients.

The authors have no proprietary interest in any aspect of this report.

1 Tong JT, Miller KM. Intraocular pressure change after sutureless phacoemulsification and foldable posterior chamber lens implantation. I Cataract Refract Surg 1998;24:256-62.

2 Handa J, Henry JC, Krupin T, et al. Extracapsular cataract extraction with posterior chamber lens implantation in patients with glaucoma. Arch Ophthalmol 1987;105:765-9.

3 Lagreze WD, Bomer TG, Funk J. Effect of surgical technique on the increase in intraocular pressure after cataract extraction. Ophthalmic Surg Lasers 1996;27:169-73.

4 Kampmeier J, Kurz S, Schütte E. Intraocular pressure after extracapsular cataract extraction with posterior chamber lens implantation: sulcus versus capsular bag fixation. Klin Monatsbl Augenheilkd 1997;211:101-5.

5 Urban V, Kammann MT, Sturmer JP. Glaucoma and cataract: combined operation or trabeculectomy first and cataract extraction later? Klin Monatsbl Augenheilkd 2000; 216:105-11.

6 Calissendorff BM, Hamberg-Nystrom H. Pressure control in glaucoma patients after cataract surgery with intraocular lens. Eur F Ophthalmol 1992;2:163-8.

prostaglandin release is greater with ECCE

than with phacoemulsification. ${ }^{3}$ In particular, the exogenous prostaglandin $\mathrm{PGF}_{2 \alpha}$ and its 
7 Savage JA, Thomas JV, Belcher CD III, et al. Extracapsular and posterior chamber intraocular lens implantation in glaucomator cyes. Ophthalmology 1

8 Gimbel HV, Meyer D, De Broff BM, et al. Intraocular pressure response to combined phacoemulsification and trabeculotomy ab externo versus phacoemulsification alone in primary open angle glaucoma. I Cataract Refract Surg 1995;21:653-60.

9 Yalvac I, Airaksinen PJ, Tuulonen A. Phacoemulsification with and without trabeculectomy in patients with glaucoma. Ophthalmic Surg Lasers 1997;28:469-75.

10 Saccà SC, Rolando M, Marletta A, et al. Fluctuations of intraocular pressure during the day in open-angle glaucoma, normal-tension glaucoma and normal subjects. $O p h$ thalmologica 1998;212:115-9.

11 Sacca SC, Macri A, Rolando M, et al. Effect of betaxolol on primary open-angle glaucoma and normal-tension glaucoma patients. F Ocul Pharmacol Ther 1998;14:191-201.

12 Zeimer RC, Wilensky JT, Gieses DK, et al. Association between intraocular pressure peaks and progression of between intraocular pressure peaks and prog
visual field loss. Ophthalmology 1991;98:64-9.

13 Cinotti DJ, Fiore PM, Maltzman BA, et al. Control of intraocular pressure in glaucomatous eyes after extracapsular cataract extraction with intraocular lens implantation. Cataract Refract Surg 1987;14:650-3.

14 Tennen DG, Masket S. Short and long term effect of clear corneal incisions on intraocular pressure. $\mathcal{F}$ Cataract Refract Surg 1996;22:568-70.

15 Kooner KS, Dulaney DO, Zimmerman TJ. Intraocular pressure following ECCE and IOL implantation in patients with glaucoma. Ophthalmic Surg 1988;19:570-4.

16 Kooner KS, Cooksey JC, Perry P, et al. Intraocular pressure following ECCE, phacoemulsification and PC-IOL implantation. Ophthalmic Surg 1988;19:643-6.

17 Hansen MH, Gylden Kerne GJ, Otland NW, et al. Intraocular pressure seven years after extracapsular extraction and sulcus implantation of posterior chamber intraocular lens. f Cataract Refract Surg 1995;21:676-8.

18 Meyer MA, Savitt ML, Kopitas E. The effect of phacoemulsification on aqueous outflow facility. Ophthalmology 1997; sification on

19 Epstain DL, Hashimoto JM, Grant WM. Serum obstruction of aqueous outflow in enucleated eyes. Am 7 Ophthalmo 1978;86:101-5.

20 Miyake K, Asakura M, Kobayashi H. Effect of intraocular lens fixation on the bood-aqueous barrier. Am $\mathcal{F}$ Ophthalmol 1984;98:451-5.

21 Spraul CW, Amman J, Lang GE, et al. Effect of cataract extraction with intraocular lens implantation on ocula hemodynamics. 7 Cataract Surg 1996;22:1091-6.

22 Wishart PK, Atkinson PL. Extracapsular cataract extraction and posterior chamber lens implantation in patients with primary chronic angle closure glaucoma: effect on intraocular pressure control. Eye 1989;3:706-12.

23 Cekic O, Batman C. Effect of capsulorhexis size on postoperative intraocular pressure. $\mathcal{f}$ Cataract Refract Surg 1999;25:416-9.

24 Steuhl KP, Marahrens P, Frohn C, et al. Intraocular pressure and anterior chamber depth before and after extracapsular cataract extraction with posterior chamber lens implantacataract extraction with posterior cham
tion. Ophthalmic Surg 1992;23:233-7.

25 Cekic O, Batman C, Totan Y, et al. Changes in anterior chamber depth and intraocular pressure after phacoemulsi- fication and posterior chamber intraocular lens implantation. Ophthalmic Surg Lasers 1998;29:639-42.

26 Storr-Paulsen A, Holger Pedersen J, Laugesen CA. Prospective study of combined phacoemulsification in cataract patients with coexisting open angle glaucoma. Acta Ophthalmol Scand 1998;76:696-9.

27 Kim DD, Doyle WJ, Smith FM. Intraocular pressure reduction phacoemulsification cataract extraction with posterior chamber lens implantation in glaucoma patient. Ophthalmic Surg Lasers 1999;30:37-40.

28 Savage JA, Thomas JV, Belcher CD, et al. Extracapsular cataract extraction and posterior chamber lens implantation in glaucomatous eyes. Ophthalmology 1985;92:150616.

29 Holst A, Rolfsen W, Svensson B, et al. Formation of free radicals during phacoemulsification. Curr Eye Res 1993;12: 359-65.

30 Laurell CG, Zetterstrom C, Philipson B, et al. Randomized study of the blood-aqueous barrier reaction after phacostudy of the blood-aqueous barrier reaction after phacoOphthalmol Scand 1998;76:573-8.

31 Miyake K, Sugiyama S, Norimatsu I, et al. Prevention of cystoid macular edema after lens extraction by topical indomethacin (III). Radioimmunoassay measurement of prostaglandins in the aqueous during and after lens extraction procedures. Graefes Arch Klin Exp Ophthalmol 1978;209:83-8.

32 Saccà SC, Patrone G, Macrì A, et al. Small incision nucleus capture: results of 200 cases. F Cataract Refract Surg 1999; 25:969-74.

33 Laurell CG, Zetterstrom C, Lundgren B, et al. Inflammatory response after phacoemulsification and lens implantation in the bag using 5.2 or $11 \mathrm{~mm}$ incision in the rabbit. $\mathcal{F}$ Cataract Refract Surg 1997;23:126-31.

34 Pande MV, Spalton DJ, Kerr-Muir MG, et al. Postoperative inflammatory response to phacoemulsification and extracapsular cataract surgery: aqueous flare and cells. 7 Cataract Refract Surg 1996;22:770-4.

35 Oshika T, Yoshimura K, Miyata N. Postsurgical inflammation after phacoemulsification and extracapsular extraction with soft or conventional intraocular lens implantation. $\mathcal{F}$ Cataract Refract Surg 1992;18:356-61.

36 Laurell CG, Zetterstrom C, Lundgren B. Phacoemulsification and lens implantation in rabbit eyes: capsular bag versus ciliary sulcus implantation and 4.0 versus $7.0 \mathrm{~mm}$ capsulorhexis. F Cataract Refract Surg 1998;24:230-6.

37 Eakins KE. Prostaglandin and nonprostaglandin mediated breakdown of the blood-aqueous barrier. Exp Eye Res $1977 ; 25: 483-98$

38 Miyake K, Mibu H, Horiguchi M, et al. Inflammatory mediators in postoperative aphakic and pseudophakic baboon eyes. Arch Ophthalmol 1990;108:1764-7.

39 Nishi O, Nishi K, Imanishi M. Synthesis of interleukin-1 and prostaglandin E2 by lens epithelial cells of human cataracts. Br 7 Ophthalmol 1992;76:338-41.

40 Yousufzai SY, Ye Z, Abdel-Latif AA. Prostaglandin F2 alpha and its analogs induce release of endogenous prostaglandins in iris and ciliary muscles isolated from cat and other mammalian species. Exp Eye Res 1996;63:305-10.

41 Kerstetter JR, Brubaker RF, Wilson SE, et al. Prostaglandin $\mathrm{F}_{2 \alpha}-1$-isopropylester lowers intraocular pressure without decreasing aqueous humor flow. Am f Ophthalmol 1988; 104:1221-7. 